\title{
DOCEAMUS
}

doceamus ... let us teach

\section{The Fulbright Specialist Program}

\author{
Noureen A. Khan
}

\begin{abstract}
The Fulbright Specialist Program sends US faculty and professionals to serve as expert consultants on curriculum, faculty development, institutional planning, and related subjects at academic institutions abroad. This manuscript describes the process and the author's assignment on remedial courses in Qatar.
\end{abstract}

The Fulbright program is the US government's flagship program in international educational exchange, administered by the Council for the International Exchange of Scholars in over 155 countries.

The Fulbright Specialist Program ${ }^{1}$ provides two- to six-week grant opportunities for US faculty and professionals. Typically Fulbright Specialists collaborate with their international counterparts on curriculum and faculty development, institutional planning, and lecture delivery. If selected, a faculty applicant becomes a "candidate" and stays on a roster for up to five years. Meanwhile, the Fulbright staff match the candidate's expertise with an overseas host institution. Some scholars may get selected from the roster once or even twice while others may not be selected at all.

When an opportunity arises, appropriate candidates are requested to develop proposals for the specific job. My host institution, Qatar University, interviewed two finalists via Skype before selecting the winner. In my case, the Fulbright office arranged the travel and the host institution graciously took care of everything and made me feel at home. I gained invaluable work experience and came to love Middle Eastern culture.

The project objective was to improve the teaching of remedial mathematics, mainly noncredit courses in

Noureen A. Khan is associate professor of mathematics at University of North Texas at Dallas. Her email address is Noureen. Khan@untda11as.edu.

${ }^{1}$ See www.cies.org/program/fulbright-specialistprogram.

For permission to reprint this article, please contact:

reprint-permission@ams.org.

DOI: http://dx.doi.org/10.1090/noti1476 college algebra and pre-calculus. The faculty participated in workshops, shared their teaching challenges during a one-on-one discussion hour, and expressed their concerns about program strengths and weaknesses. I visited classes to gauge program effectiveness and possible areas of improvement. My biggest challenge was how to approach the traditional mindset of mathematics teachers in a Middle Eastern country where straight lecturing, rote memorization, and repetition were the rule. The teachers gave the students formulas and steps for solving algebra problems to memorize. Students copied notes from the board and did algebra drill exercises.

My open-door discussion hours had a relaxed atmosphere, where faculty felt free to share their feelings, achievements, and concerns. Because of this relaxed atospehere, we were able to also discuss possible solutions to address many of their concerns.

I designed a strategic process to follow "best practices" and created an online forum to share ideas and teaching challenges. I encouraged a move away from the one-size-fits-all model to group instruction in order to accommodate the varying levels of learner, some faster some slower, and toward self-paced learning during lab hours. My biggest accomplishment was building trust and long-lasting relationships with faculty,

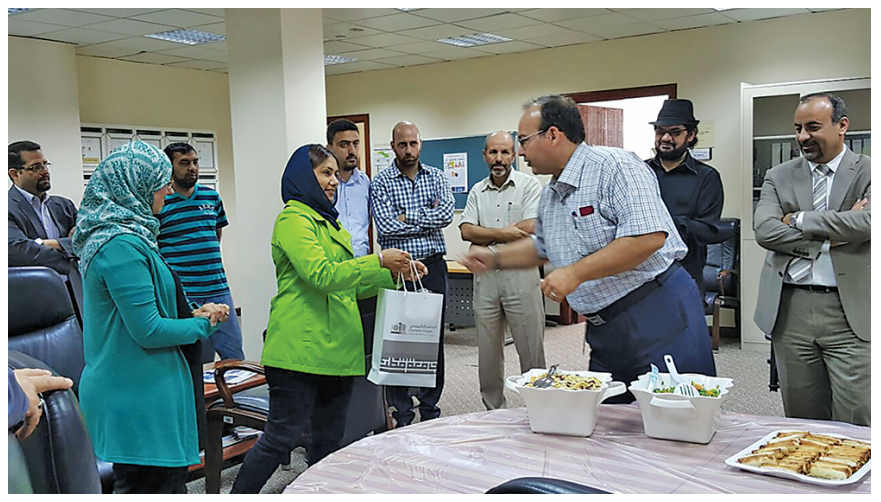

Director of the Foundation Program, Dr. Nadeem Hashem, thanks Khan before the faculty for her kind work at Qatar University. 


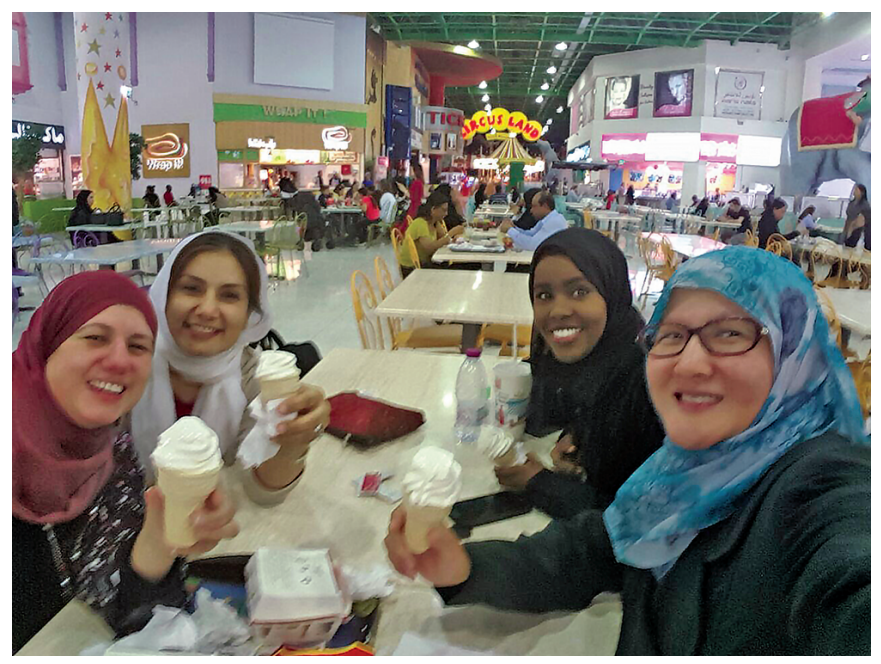

Khan (second from left) enjoys ice cream with teachers Lina Khalaf, Heba Ahmed Gulied, and Sarah Aw Swee Hwa at City Mall Doha in Qatar.

giving me the memories of a lifetime. At a final meeting, the Vice President and Chief Academic Officer of Qatar University told me, "We appreciate your dedication and hard work on this project. You brought motivation to teach to our faculty. More importantly, for the first time, nobody felt offended by your class visits. We want you on our team." I am invited for a second Fulbright visit next year, and I can't wait to go back.

Meanwhile, back at home, I have become very invested in innovative methods of teaching remedial courses. And to my surprise, I have learned ways to improve my own teaching and gained a new appreciation for the support innovation regularly receives in the United States.

\section{Photo Credits}

Photo of Noureen Khan is courtesy of UNT Dallas. All other article photos are courtesy of the author.

ACKNOWLEDGMENT. This project was supported by Fulbright Global Program, the Council for International Exchange of Scholars, and the Foundation Program, Qatar University.

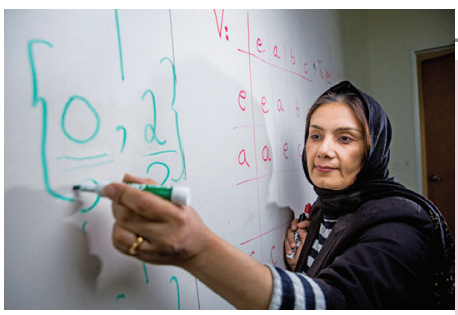

Noureen A. Khan

weeks in Qatar as a Fulbright Specialist.

After studies at Bahauddin Zakariya University, Pakistan, Khan got her $\mathrm{PhD}$ from the University of Texas at Dallas, where she is now on the faculty. In 2016, she spent four

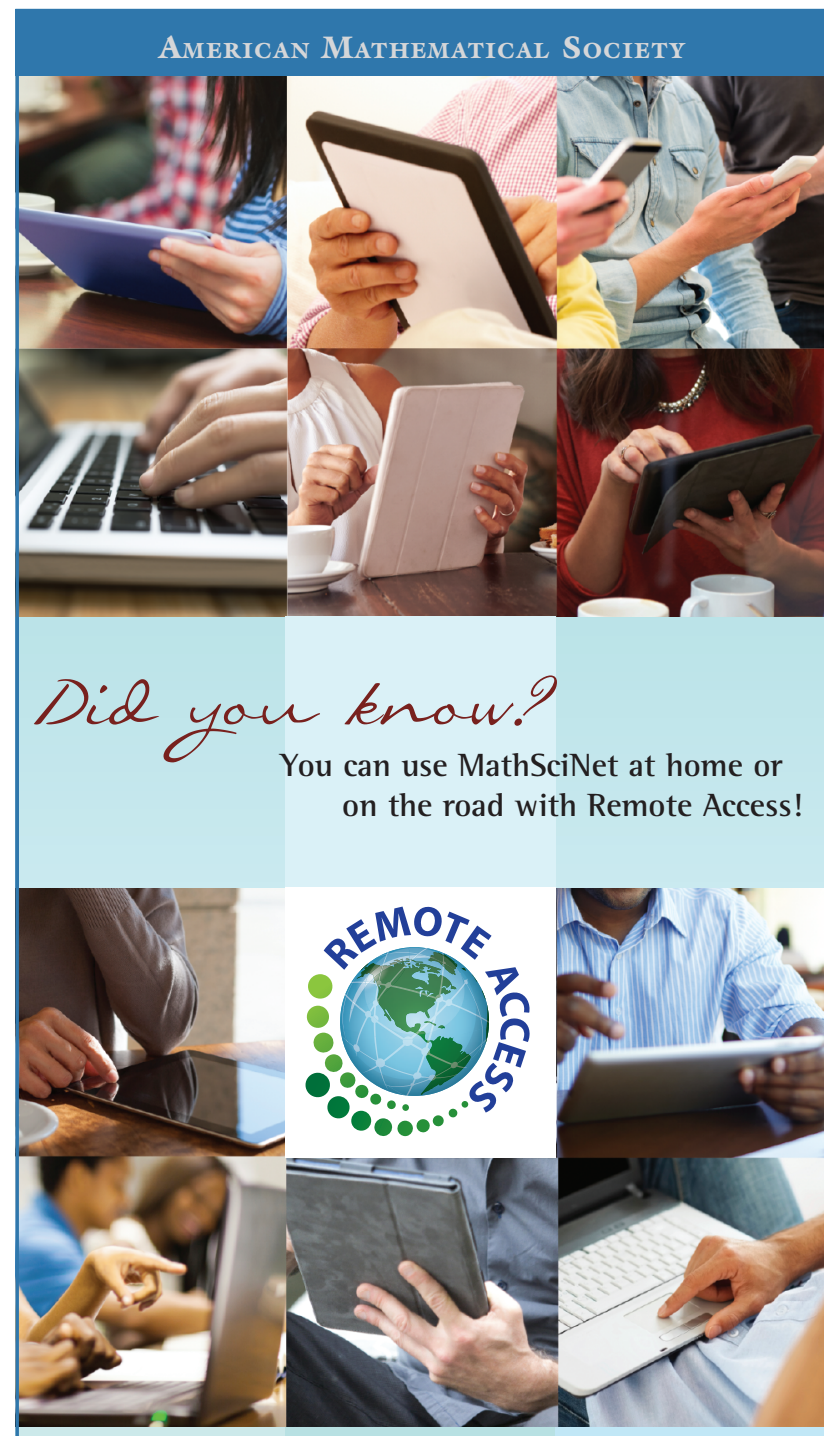

Remote Access is a mechanism by which users can pair various web browsing devices (smartphones, tablets, laptops, desktops) with an institution's network, allowing users to access AMS electronic products when not connected to a host institution's network. The AMS permits authorized users (faculty, staff, students, and visiting faculty) to pair mobile devices with a host institution's subscriptions.

For more information, visit: Mathscinet Mathematical Reviews 